\title{
Effect of digoxin on ventricular automaticity in Chagasic cardiomyopathy
}

NUSEN BEER

M.D.

José M. Aparicio

M.D.
J. J. Puigbó

M.D.

\section{EDUARDO HIRSCHHAUT}

M.D.

\section{RAFAel VALecillos}

M.D.

\section{Laboratorio de Exploración Cardiopulmonar, Hospital Universitario de Caracas, Venezuela}

TWENTY-ONE patients with serologically proved Chagas' disease were studied to determine the effect of digoxin on cardiac rhythm. Full clinical investigations were carried out in all patients, including the multistage exercise test (Bruce), aiming at inducing or increasing ventricular arrhythmia. Only thirteen patients had evidence of Chagasic cardiomyopathy. Every patient received orally digoxin $0.25 \mathrm{mg}$ daily for 10 days. Serum digoxin levels were measured using radioimmunoassay techniques. The exercise test was repeated after a 10-day period of treatment.

\section{Results}

(1) Serum levels were at the lower limits of therapeutic serum concentrations (mean, $0.48 \mathrm{ng} / \mathrm{ml}$; range, $0 \cdot 2-1 \cdot 0 \mathrm{ng} / \mathrm{ml}$ ).

(2) Working capacity (FAI $=$ functional aerobic impairment) after oral digoxin:

(i) Among the group of eleven patients without cardiomegaly, five showed an improvement of $30 \%$ of the working capacity: in five there were no changes and in one there was a decrease of $10 \%$. (ii) Among the seven patients with cardiomegaly, five showed an improvement of $25 \%$ of the working capacity; one patient experienced no change and in another, ventricular tachycardia and ventricular bigeminy with marked decrease of $50 \%$ of working capacity occurred.

(3) Ventricular arrhythmias after oral digoxin:

(i) In thirteen patients without cardiomegaly there was no significant increase in the number of ventricular extrasystoles during the four stages of Bruce's test.

(ii) In eight patients with cardiomegaly there was a significant increase of the number of ventricular extrasystoles in the first stage of Bruce's test $(P<$ $0.01)$. During the second stage there was a decrease in the number of ventricular extrasystoles. In the third and fourth stages no significant changes of ventricular extrasystoles were found ( $P$ not significant).

It is concluded that oral digoxin ( $0.25 \mathrm{mg}$ daily) is probably an effective and safe drug in the treatment of chronic Chagasic cardiomyopathy. 